\title{
THE TREE DON'T CARE WHAT THE LITTLE BIRD SINGS: THE AMERICAN PUBLIC OPINION AND EDWARD SNOWDEN
}

\begin{abstract}
By making Americans aware of a secret government surveillance program targeting their electronic communications, Edward Snowden intended to kickstart a public debate on the nature of democratic governance. His intentions are likely to hit a wall of indifference. Why? The answer may lie in the American political culture.
\end{abstract}

\section{Key words}

Snowden, surveillance, NSA, security, privacy, political culture, schizophrenic politics, war on terror

The more clandestine intelligence operations are, the more we need rigorous vigilance to ensure that the ends do not corrupt the means. Otherwise we start to look like our enemies.

Adam Hochschild, Harper's Magazine, 2015.

Men are so simple-minded and so controlled by their immediate needs that he who deceives will always find someone who will let himself be deceived.

Niccolò Machiavelli, The Prince, 1513.

\section{Yes, we scan!}

I am typing these words on a computer connected to a high-speed modem. I collected most of the information for this text online. I discussed parts of this article with my colleagues on Skype. I communicated with the editor of this journal USA.

* Jacek Dalecki, Department of Political Science, Indiana University Bloomington, 